\title{
ESTRUTURA E FUNCIONAMENTO DOS NÚCLEOS DE ACESSIBILIDADE NAS UNIVERSIDADES FEDERAIS DA REGIÃO SUDESTE
}

\author{
ESTRUCTURA Y EL FUNCIONAMIENTO DE LOS NÚCLEOS DE \\ ACCESIBILIDAD EN LAS UNIVERSIDADES FEDERALES DE LA REGIÓN \\ SURESTE
}
STRUCTURE AND FUNCTIONING OF THE ACCESSIBILITY CENTERS ON FEDERAL UNIVERSITIES OF THE SOUTHEAST REGION

RESUMO: Este artigo apresenta resultados de uma pesquisa sobre a estrutura e o funcionamento dos Núcleos de Acessibilidade (NA) de 19 Universidades Federais da Região Sudeste. Em termos metodológicos, adotamos a pesquisa quantitativa e descritiva. Como procedimentos de coleta de dados aplicamos um questionário respondido pelos coordenadores dos NA por meio eletrônico. Os resultados evidenciaram, entre outros aspectos, as dificuldades e as escolhas realizadas pelas instituições federais para garantir a acessibilidade ao ensino superior de discentes com deficiências, transtornos globais do desenvolvimento e com altas habilidades/superdotação. Igualmente, mostraram a constituição das equipes que atuam nos NA e as ações que as mesmas vem desenvolvendo para garantir o acesso e a participação plena dos discentes nas atividades acadêmicas.

PALAVRAS-CHAVE: Políticas de inclusão no ensino superior. Núcleos de acessibilidade. Região sudeste.

RESUMEN: Este artículo presenta resultados de una investigación sobre la estructura y el funcionamiento de los Núcleos de Accesibilidad (NA) en 19 Universidades Federales de la Región Sureste. En términos metodológicos, adoptamos la investigación cuantitativa y descriptiva. Como procedimiento de recolección de datos, aplicamos un cuestionario electrónico respondido por los coordinadores de los NA. Los resultados evidenciaron, entre otros aspectos, las dificultades y las elecciones realizadas por las instituciones federales para garantizar la accesibilidad a la enseñanza superior de discentes con discapacidades, trastornos globales del desarrollo y con altas habilidades / superdotación. Igualmente, mostraron la constitución de los equipos que actúan en los NA y las acciones que las mismas vienen desarrollando para

\footnotetext{
1 Universidade Federal Rural do Rio de Janeiro (UFRRJ), RJ - Brasil. Professora Associada do Departamento Educação e Sociedade e do Programa de Pós-Graduação em Educação, Contextos Contemporâneos e Demandas Populares (PPGEduc). E-mail: marciadenisepletsch@gmail.com

${ }^{2}$ Universidade Federal do Rio Grande do Norte (UFRN), RN - Brasil. Professor Associado do Departamento de Fisioterapia e do Programa de Pós-Graduação em Educação (PPGED). E-mail: Contato: ricardolins67@gmail.com.
} 
garantizar el acceso y la participación plena de los alumnos, en las actividades académicas.

PALABRAS CLAVE: Políticas de inclusión en la enseñanza superior. Núcleos de accesibilidad. Región sureste.

ABSTRACT: This article presents results of a research on the structure and functioning of the Accessibility Centers (NA) of 19 Federal Universities of the Southeast Region. This is a quantitative and descriptive research. As data collection procedures we applied a questionnaire answered by the NA coordinators by done electronically. The results showed, among other aspects, the difficulties and the choices made by federal institutions to guarantee the accessibility to higher education of students with disabilities, global developmental disorders and with high skills/giftedness. Likewise, they showed the constitution of the teams that work in the NA and the actions that they have been developing to guarantee the access and full participation of the students in the academic activities.

KEY WORDS: Inclusion policies in higher education. Accessibility centers. Southeast region.

\title{
Introdução
}

\begin{abstract}
A inclusão das pessoas com deficiência na educação superior deve assegurar-lhes o direito à participação na comunidade com as demais pessoas, as oportunidades de desenvolvimento pessoal, social e profissional, bem como não restringir sua participação em determinados ambientes e atividades com base na deficiência. [...] Para a efetivação deste direito, as IES devem disponibilizar serviços e recursos de acessibilidade que promovam a plena participação dos estudantes (BRASIL, 2013, s/p).
\end{abstract}

As condições de acessibilidade presentes nas estruturas físicas das instituições, como escolas e universidades devem estar relacionadas às políticas inclusivas das estruturas administrativas, que devem refletir uma atitude de luta contra a exclusão. Porém, a cultura de incorporar o outro, o diferente, ainda está sendo formada. (MANZINI, 2005, p. 32).

A partir da década de 2000, a inclusão de pessoas com deficiências no ensino superior vem ganhando relevo nas discussões acadêmicas e nas diretrizes políticas. Inúmeras iniciativas têm sido adotadas deste então para ampliar os direitos educacionais e sociais das pessoas com deficiências, transtornos globais do desenvolvimento e altas habilidades/superdotação. 
Uma iniciativa importante nesse sentido foi o Programa de Acessibilidade na Educação Superior, conhecido como Programa Incluir $^{3}$, criado em 2005 pela então Secretaria de Educação Especial, extinta em 2014, em parceria com a Secretaria de Ensino Superior, ambos vinculados ao Ministério da Educação (MEC). O objetivo principal do Programa Incluir era fomentar a criação e a consolidação de núcleos de acessibilidade nas instituições federais de ensino superior (IFEs) para efetivar a inclusão de pessoas com deficiência à vida acadêmica, eliminando barreiras comportamentais, pedagógicas, arquitetônicas e de comunicação (BRASIL, 2013). Até 2015 foram contempladas 63 IFES, que receberam investimentos de R\$ 53.696.000,00 (BRASIL, 2016a).

Na análise de Melo (2015; 2016), o Programa Incluir além de ser uma referência, pode ser considerado um “divisor de águas” no que diz respeito à inclusão de pessoas com deficiências no ensino superior. Os autores defendem que o Programa influenciou, sobremaneira, a inserção do tema na Política Nacional de Educação Especial na Perspectiva da Educação Inclusiva (BRASIL, 2008a), sobretudo ao inserir a proposta da inclusão desde os anos iniciais até o ensino superior, o qual, por sua vez, segue as orientações da Convenção das Nações Unidas sobre os Direitos das Pessoas com Deficiência, realizada em 2007 nos Estados Unidos. Vale mencionar que a referida Convenção foi incorporada como emenda Constitucional no Brasil pelo Decreto $\mathrm{n}^{\circ}$. 6.949/ 2009 da Casa Civil (BRASIL, 2009).

Ainda sobre o Programa Incluir é importante dizer que, de 2005 a 2011, os recursos orçamentários eram liberados a partir da participação das IFEs em editais públicos. Com o Decreto $n^{\circ}$. 7. 611 de 17 de novembro de 2011, as IFEs passaram a ter dotação orçamentária para desenvolver ações para a permanência dos discentes com deficiência no ensino superior (BRASIL, 2011). Em nossa análise, a dotação orçamentária específica para ações na área da inclusão no ensino superior foi e continua sendo fundamental para que as IFEs elaborem ações e diretrizes institucionais de acessibilidade física e suporte pedagógico para os discentes com deficiências que ingressam no ensino superior. O Programa também objetivou contribuir com a instalação de Núcleos de Acessibilidade nas IFES, caracterizados pela Secretaria de Educação Superior como:

\footnotetext{
${ }^{3}$ Ainda sore o Programa Incluir indicamos as pesquisas de Souza (2010), Bruno (2011) e Melo (2015).

${ }^{4}$ Desde a sua extinção as ações de Educação Especial foram incorporadas por meio de uma coordenadoria na Secretaria de Educação Continuada, Alfabetização, Diversidade e Inclusão (SECADI).
} 
Espaço físico, com profissional responsável pela organização das ações, articulação entre os diferentes órgãos e departamentos da universidade para a implementação da política de acessibilidade e efetivação das relações de ensino, pesquisa e extensão na área (BRASIL, 2008b, p 39).

Outra iniciativa importante no que diz respeito à garantia dos direitos sociais e educacionais da população alvo da Educação Especial é a Lei Brasileira de Inclusão (LBI), ou Estatuto da Pessoa com Deficiência (Lei no . 13.146, de 6 de julho de 2015), que entrou em vigor em janeiro de 2016. Sobre o ensino superior, a LBI traz em seu artigo 30 um conjunto de diretrizes em relação aos processos seletivos para ingresso e permanência nos cursos oferecidos pelas instituições de ensino superior e de educação profissional e tecnológica, públicas e privadas, como pode-se ver no trecho coligido a seguir:

I - atendimento preferencial à pessoa com deficiência nas dependências das Instituições de Ensino Superior (IES) e nos serviços; II - disponibilização de formulário de inscrição de exames com campos específicos para que o candidato com deficiência informe os recursos de acessibilidade e de tecnologia assistiva necessários para sua participação;

III - disponibilização de provas em formatos acessíveis para atendimento às necessidades específicas do candidato com deficiência;

IV - disponibilização de recursos de acessibilidade e de tecnologia assistiva adequados, previamente solicitados e escolhidos pelo candidato com deficiência;

$\mathrm{V}$ - dilação de tempo, conforme demanda apresentada pelo candidato com deficiência, tanto na realização de exame para seleção quanto nas atividades acadêmicas, mediante prévia solicitação e comprovação da necessidade;

VI - adoção de critérios de avaliação das provas escritas, discursivas ou de redação que considerem a singularidade linguística da pessoa com deficiência, no domínio da modalidade escrita da língua portuguesa;

VII - tradução completa do edital e de suas retificações em Libras (BRASIL, 2015).

Em termos de avanços legais para a garantia de acesso da população alvo deste artigo no ensino superior, em 2017 foi sancionada a Lei $n^{\circ}$. 13.409, de 28 de dezembro de 2016, que altera a Lei $\mathrm{n}^{\mathrm{o}} 12.711$, de 29 de agosto de 2012, para dispor sobre a reserva de vagas para pessoas com deficiência nos cursos técnico de nível médio e superior das instituições federais de ensino. É a chamada lei de cotas para pessoas com deficiências (BRASIL, 2016b; 2012a). 
Essas mudanças legais têm colocado novos desafios para as IES em relação à inclusão de pessoas com deficiência e transtornos globais do desenvolvimento. $\mathrm{O}$ conjunto de ações governamentais tem ampliado o acesso dessa população no ensino superior. De acordo com os indicadores analisados por Martins, Leite e Broglia (2015) e Pletsch e Leite (2017), a partir de dados do Instituto Nacional de Estudos e Pesquisas Nacionais Anísio Teixeira (INEP), houve um crescimento de 85,35\% de matrículas entre os anos de 2004 a 2014. De acordo com as autoras, o aumento foi expressivo, em torno de 520\%, atingindo 33.377 matrículas. No entanto, em que pesem os avanços legais, a participação dessa população atingiu apenas $0,37 \%$ da participação no ensino superior ao montante de estudantes que se encontram nessa condição. Essa realidade evidencia que, a partir de 2017, com a Lei de Cotas de pessoas com deficiências no ensino superior, as IES enfrentarão novos desafios para garantir o acesso, a permanência e a plena participação nas atividades de ensino, pesquisa e extensão desse grupo social.

Tomando como base os avanços legais e as perspectivas e desafios a serem enfrentados pelas universidades, em 2014, no contexto da organização e realização do I Congresso Nacional de Inclusão na Educação Superior e Educação Profissional Tecnológica, foi realizado um levantamento pela Comissão Permanente de Apoio aos Estudantes com Necessidades Educacionais Especiais (CAENE) da Universidade Federal do Rio Grande do Norte (UFRN), coordenado pelo Professor Francisco Ricardo Lins Vieira de Melo. A pesquisa seguiu os procedimentos éticos contidos na Resolução $n^{\circ} 466 / 2012$ do Conselho Nacional de Saúde, que fundamenta as pesquisas envolvendo seres humanos no Brasil (BRASIL, 2012), e teve a anuência formal de todos os participantes. Além do Termo de Consentimento Livre e Esclarecido assinado pelos coordenadores dos núcleos de acessibilidade.

A pesquisa realizou um panorama das ações de inclusão no ensino superior desenvolvidas por universidades federais. Para tal, adotou como procedimento de coleta de dados um questionário online, o qual foi enviado para 63 universidades federais, com retorno de $100 \%$ dos questionários. No entanto, apenas 54 afirmaram ter no ano da pesquisa (2014) Núcleos de Acessibilidade. Resultados discutindo aspectos regionais e nacionais envolvendo dados da pesquisa já foram publicados por Saraiva (2015), Melo (2015; 2016) e Cabral e Melo (2017).

Este artigo pretende apresentar uma análise das dezenove (19) universidades federais da região Sudeste que responderam o questionário. Nosso foco será analisar a 
estrutura e o funcionamento dos Núcleos de Acessibilidade destas instituições5. Acreditamos que esta discussão pode contribuir não apenas para ampliar o conhecimento sobre como as IES tem se organizado para receber discentes com alguma deficiência, mas também, pode contribuir para a elaboração de propostas pedagógicas e politicas institucionais que ampliem as condições de acesso, permanência e participação dos discentes com deficiências nas atividades acadêmicas.

\section{Aspectos metodológicos}

Para atingir os objetivos de nossa proposta, usaremos dados de um levantamento quantitativo realizado no ano de 2014, por meio de um questionário respondido online por dezenove instituições federais de ensino superior, localizadas na região Sudeste. As dezenove universidades que responderam o questionário foram:

- Universidade Federal Fluminense (UFF) - Campus de Campos de Goytacazes;

- Universidade Federal do Estado do Rio de Janeiro (UNIRIO);

- Universidade Federal do Rio de Janeiro (UFRJ);

- Universidade Federal Rural do Rio de Janeiro (UFRRJ) - Campus de Nova Iguaçu;

- Universidade Federal de São Paulo (UNIFESP);

- Universidade Federal de São Carlos (UFScar);

- Universidade Federal do ABC Paulista (UFABC);

- Universidade Federal do Espírito Santo (UFES);

- Universidade Federal do Vale do Jequitinhonha e Mucuri (UFVJM);

- Universidade Federal de Lavras (UFL);

- Universidade Federal de Itajubá (UNIFEI);

- Universidade Federal do Juiz de Fora (UFJF);

- Universidade Federal de Viçosa (UFV);

- Universidade Federal do Triângulo Mineiro (UFTM);

- Universidade Federal de Ouro Preto (UFOP);

- Universidade Federal de Uberlândia (UFU);

- Universidade Federal de Minas Gerais (UFMG);

- Universidade Federal de Alfenas (UFAL);

- Universidade Federal de São João Del-Rei (UFSJ).

O questionário respondido pelos coordenadores dos núcleos de acessibilidade foi organizado em três partes, caracterizando: a) o coordenador do núcleo de acessibilidade; b) as universidades federais participantes; c) a estrutura e o funcionamento dos núcleos

${ }^{5}$ Uma análise detalhada está sendo realizada por Moreira (2017) em sua dissertação de mestrado. 
de acessibilidade. Os dados obtidos foram organizados e analisados por meio de análise quantitativa descritiva, utilizando recursos do Programa Microsoft Excel, conforme descrito por Melo, Martins e Martins (2017).

A região Sudeste é formada por quatro estados (Rio de Janeiro, São Paulo, Minas Gerais e Espírito Santo), apresenta o maior índice populacional e é o principal polo industrial do Brasil, sendo responsável por quase $60 \%$ do Produto Interno Bruto (PIB). Para sistematizar informações sobre a referida região, apresentamos a seguir um quadro elaborado por Moreira (2017).

Quadro 1. Características da Região Sudeste

\begin{tabular}{|c|c|c|c|c|c|c|}
\hline \multicolumn{7}{|c|}{ Características da Região Sudeste } \\
\hline Estado e Capital & $\begin{array}{c}\text { Densidade } \\
\text { demográfica }\end{array}$ & $\begin{array}{l}\text { Extensão } \\
\text { territorial }\end{array}$ & Municípios & População & IDH & $\begin{array}{c}\text { Partic. } \\
\text { no PIB } \\
\text { regional }\end{array}$ \\
\hline $\begin{array}{c}\text { Espírito Santo } \\
\text { Vitória }\end{array}$ & $76,2 \mathrm{hab} / \mathrm{km}^{2}$. & $\begin{array}{l}46.098,571 \\
\mathrm{~km}^{2} .\end{array}$ & 78 & $\begin{array}{l}3.514 .952 \\
\text { habitantes. }\end{array}$ & $\begin{array}{c}0,802 \\
7^{\circ} \text { posição } \\
\text { nacional }\end{array}$ & $4 \%$. \\
\hline $\begin{array}{c}\text { Minas Gerais } \\
\text { Belo Horizonte. }\end{array}$ & $33,4 \mathrm{hab} / \mathrm{km}^{2}$. & $\begin{array}{l}586.520,36 \\
8 \mathrm{~km}^{2} .\end{array}$ & 853. & $\begin{array}{l}19.597 .330 \\
\text { habitantes. }\end{array}$ & $\begin{array}{c}0,800 \\
10^{\circ} \text { posição } \\
\text { nacional }\end{array}$ & $16,1 \%$. \\
\hline $\begin{array}{l}\text { São Paulo } \\
\text { São Paulo }\end{array}$ & $\begin{array}{c}166,2 \\
\mathrm{hab} / \mathrm{km}^{2}\end{array}$ & $\begin{array}{c}248.196,96 \\
0 \mathrm{~km}^{2} .\end{array}$ & 645. & $\begin{array}{l}41.262 .199 \\
\text { habitantes. }\end{array}$ & $\begin{array}{c}0,833\left(3^{\circ}\right. \\
\text { posição } \\
\text { nacional). }\end{array}$ & $60,1 \%$. \\
\hline $\begin{array}{l}\text { Rio de Janeiro } \\
\text { Rio de Janeiro }\end{array}$ & $\begin{array}{c}365,2 \\
\mathrm{hab} / \mathrm{km}^{2} .\end{array}$ & $\begin{array}{c}43.780,157 \\
\mathrm{~km}^{2}\end{array}$ & 92 & $\begin{array}{l}15.989 .929 \\
\text { habitantes. }\end{array}$ & $\begin{array}{c}0,832\left(4^{\circ}\right. \\
\text { posição } \\
\text { nacional }) .\end{array}$ & $19,8 \%$. \\
\hline
\end{tabular}

Fonte: Moreira (2017) - adaptado pelos autores

A região Sudeste também tem o maior número de matrículas no ensino superior nacional (com 3.034 milhões de matrículas somente em cursos presenciais), totalizando aproximadamente $47 \%$ do total (MOREIRA, 2017). A seguir, apresentamos os resultados de nossa pesquisa.

\section{Resultados e discussão}

Iniciamos pela vinculação institucional dos núcleos. Das dezenove universidades, oito apresentam NA vinculados à Pró-Reitoria de Assuntos Estudantis, quatro à Pró-Reitoria de Extensão e Assuntos Comunitários, três à Pró-Reitoria de Graduação, um à Reitoria, um à Faculdade de Educação, um à Secretaria de Desenvolvimento Institucional e um à Superintendência Geral de Políticas Estudantis. 
Dos dezenove questionários, apenas um foi respondido pelo representante da Pró-Reitoria de Extensão, que afirmou não existir um núcleo de acessibilidade em sua instituição. Dos coordenadores que responderam, três eram do gênero masculino e quinze do gênero feminino. Também verificamos uma variedade de formações. A tabela a seguir apresenta o perfil dos coordenadores de núcleos de acessibilidade das universidades federais do Sudeste.

Tabela 1: Perfil dos coordenadores de núcleos de acessibilidade das universidades federais do sudeste brasileiro

\begin{tabular}{|c|c|c|}
\hline Características & & Número \\
\hline Gênero & $\begin{array}{l}\text { Feminino } \\
\text { Masculino }\end{array}$ & $\begin{array}{c}15 \\
4\end{array}$ \\
\hline Formação Acadêmica & $\begin{array}{l}\text { Pedagogia } \\
\text { Letras } \\
\text { Psicologia } \\
\text { Letras e Pedagogia } \\
\text { Física } \\
\text { Geografia } \\
\text { Ciências Sociais } \\
\text { Terapia Ocupacional } \\
\text { Nutrição } \\
\text { Educação Física } \\
\text { Educação Especial } \\
\text { Administração }\end{array}$ & $\begin{array}{l}2 \\
1 \\
3 \\
1 \\
2 \\
1 \\
1 \\
2 \\
1 \\
2 \\
1 \\
1\end{array}$ \\
\hline Pós-Graduação & $\begin{array}{l}\text { Doutorado } \\
\text { Doutorado em andamento } \\
\text { Mestrado } \\
\text { Especialização } \\
\text { Não informou }\end{array}$ & $\begin{array}{c}10 \\
1 \\
4 \\
3 \\
1 \\
\end{array}$ \\
\hline $\begin{array}{l}\text { Formação na área de } \\
\text { Educação Especial/Inclusiva }\end{array}$ & $\begin{array}{l}\text { Sim } \\
\text { Não }\end{array}$ & $\begin{array}{c}15 \\
4\end{array}$ \\
\hline Função exercida na IES & $\begin{array}{l}\text { Docente } \\
\text { Técnico-administrativo }\end{array}$ & $\begin{array}{c}11 \\
6 \\
\end{array}$ \\
\hline $\begin{array}{l}\text { Tempo de atuação como } \\
\text { coordenador de núcleo }\end{array}$ & 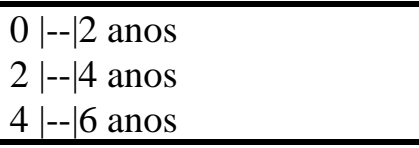 & $\begin{array}{c}14 \\
2 \\
2 \\
\end{array}$ \\
\hline Experiência em gestão & $\begin{array}{l}\text { Sim } \\
\text { Não }\end{array}$ & $\begin{array}{c}13 \\
6\end{array}$ \\
\hline $\begin{array}{l}\text { Experiência profissional com } \\
\text { pessoas com deficiência }\end{array}$ & $\begin{array}{l}\text { Sim } \\
\text { Não }\end{array}$ & $\begin{array}{c}18 \\
1\end{array}$ \\
\hline
\end{tabular}

Fonte: Elaboração própria.

Como podemos depreender da tabela 01 , do total de coordenadores de núcleos, seis eram técnicos administrativos, sendo três com especialização, dois com mestrado e

${ }^{6}$ Nesta categoria excluímos o questionário respondido pela Pró-Reitoria de Extensão. 
um não informou a formação. Dos onze docentes que responderam, dez eram doutores, um estava finalizando o doutorado e dois possuíam mestrado. Do total de coordenadores, quinze possuíam alguma formação na área de educação especial e inclusiva e, dos quatro que não possuíam formação na área, sinalizaram ter experiência na gestão administrativa, sendo que um possui deficiência. Para Melo, Martins e Martins (2017), a formação docente dos coordenadores é importante, pois a experiência no ensino, pesquisa e extensão são fundamentais para articular as diferentes dimensões da vida acadêmica dos estudantes que recebem apoio do núcleo. Em relação ao tempo de atuação como coordenadores de núcleos, quatorze atuam há menos de dois anos como coordenadores, dois atuam há mais de dois anos e dois entre quatro e seis anos.

Segundo os participantes da pesquisa, os núcleos atendiam em 2014853 estudantes, sendo 146 com deficiência auditiva, 27 com surdez, 239 com baixa visão, 65 com cegueira, 222 com deficiência física, 53 com deficiência intelectual, 22 com deficiência múltipla, 5 com Asperger/ autismo, 9 com altas habilidades/superdotação e 47 com outras necessidades educacionais especiais. Aqui é importante destacar que esses dados dizem respeito aos atendimentos realizados pelos núcleos. Essa ressalva é importante, pois os dados divergem em relação ao número de matrículas de pessoas com deficiências no ensino superior. Por exemplo, a pesquisa de Reis (2010) realizada nas universidades federais de Minas Gerais evidenciou que, somente no ano de 2007, foram matriculadas mais de três mil pessoas com necessidades educacionais especiais. Temos duas hipóteses sobre essa discrepância nos dados. A primeira é de que a maioria dos estudantes não demanda apoio especializado dos núcleos e, a segunda, de que os núcleos ainda estavam se estruturando na maioria das universidades; àquela altura estavam ainda sem recursos técnicos e humanos para mapear os discentes com deficiências, transtornos globais do desenvolvimento e altas habilidades/superdotação.

Verificamos que os núcleos realizam um conjunto de atividades, que vão desde a participação em processos seletivos de ingresso ao ensino superior até formações continuadas sobre inclusão e acessibilidade e assessoramento pedagógico a coordenadores e professores com discentes com deficiências matriculados em suas turmas. $\mathrm{O}$ quadro a seguir sintetiza tais informações sobre as ações desenvolvidas pelos NA nas universidades que participaram da pesquisa. 
Quadro 2. Ações desenvolvidas pelos Núcleos de Acessibilidades das universidades federais do sudeste

\begin{tabular}{|c|c|c|c|}
\hline \multirow[b]{2}{*}{ Ações desenvolvidas } & \multicolumn{3}{|c|}{ Na de Núcleos de Acessibilidade } \\
\hline & Não & $\begin{array}{c}\text { Efetivadas } \\
\text { parcialmente }\end{array}$ & $\begin{array}{c}\text { Efetivadas } \\
\text { integralmente }\end{array}$ \\
\hline $\begin{array}{l}\text { Participação em processos seletivos promovendo } \\
\text { acessibilidade }\end{array}$ & 3 & 12 & 4 \\
\hline $\begin{array}{l}\text { Assessoramento pedagógico aos professores e } \\
\text { coordenadores de cursos da instituição no que tange a } \\
\text { acessibilidade e inclusão }\end{array}$ & 5 & 11 & 3 \\
\hline $\begin{array}{l}\text { Formação sobre acessibilidade e inclusão do corpo } \\
\text { docente e corpo técnico da instituição. }\end{array}$ & 5 & 13 & 1 \\
\hline Orientações para usabilidade de tecnologia assistiva & 5 & 10 & 4 \\
\hline $\begin{array}{l}\text { Disponibilização de recursos de tecnologia assistiva para } \\
\text { uso dos estudantes com deficiência }\end{array}$ & 1 & 13 & 5 \\
\hline $\begin{array}{l}\text { Produção de material didático em diferentes formatos } \\
\text { acessíveis }\end{array}$ & 6 & 12 & 1 \\
\hline $\begin{array}{l}\text { Organização e oferta do Atendimento Educacional } \\
\text { Especializado - AEE }\end{array}$ & 9 & 9 & 1 \\
\hline Orientação às famílias & 12 & 4 & 3 \\
\hline $\begin{array}{l}\text { Desenvolvimento de projetos de ensino (monitoria, } \\
\text { tutoria, voluntariado, entre outros) para apoio acadêmico } \\
\text { de estudantes público-alvo da educação especial }\end{array}$ & 5 & 10 & 4 \\
\hline $\begin{array}{l}\text { Desenvolvimento de projetos de pesquisa sobre inclusão } \\
\text { e acessibilidade no ensino superior }\end{array}$ & 6 & 8 & 5 \\
\hline $\begin{array}{l}\text { Desenvolvimento de projetos de extensão sobre inclusão } \\
\text { e acessibilidade envolvendo a participação da } \\
\text { comunidade }\end{array}$ & 4 & 10 & 5 \\
\hline Aquisição de recursos de tecnologia assistiva & 6 & 12 & 1 \\
\hline $\begin{array}{l}\text { Articulação com gestores para implementação de ações } \\
\text { afirmativas (cotas para estudantes com deficiência, bolsa } \\
\text { de auxílio financeiro para estudantes com deficiência, } \\
\text { entre outras) }\end{array}$ & 3 & 10 & 6 \\
\hline $\begin{array}{l}\text { Política de ações afirmativas com cotas para discentes } \\
\text { com deficiência, transtorno global do desenvolvimento } \\
\text { ou altas habilidades/superdotação } \\
\text { PRODOCÊNCIA, PET, PROEX, entre outros). }\end{array}$ & 9 & 8 & 2 \\
\hline Total & 79 & 169 & 44 \\
\hline
\end{tabular}

Fonte: Elaboração própria.

Como podemos verificar, de maneira geral, os núcleos das universidades federais do Sudeste desenvolvem diferentes ações para a promoção do acesso e da permanência dos estudantes com deficiências no ensino superior, mas a maioria dessas 
ações (169) é efetivada apenas parcialmente. Somente 44 são efetivadas integralmente e 49 não são desenvolvidas por nenhum dos núcleos. Infelizmente, dados quantitativos não nos dão a real dimensão das ações cotidianas desenvolvidas pelos núcleos. Para tal, pesquisas qualitativas como as de Duarte (2009), Moreira (2015), Silva (2016) e Pereira (2017) podem contribuir para conhecer as realidades das instituições e o dia a dia das pessoas com deficiências, suas dificuldades e desafios enfrentados para vivenciar as atividades acadêmicas ${ }^{7}$.

Também perguntamos como os coordenadores dos núcleos avaliavam a acessibilidade atitudinal, arquitetônica, pedagógica, programática, transportes, instrumental e comunicacional. O quadro três sintetiza as respostas dos participantes.

Quadro 3. Condições de acessibilidade nas IFEs da região Sudeste

\begin{tabular}{|c|c|c|c|c|c|}
\hline Acessibilidade & Péssima & Ruim & Regular & Bom & Excelente \\
\hline Atitudinal & 1 & 4 & 11 & 1 & 1 \\
\hline Arquitetônica & 2 & 5 & 7 & 4 & 2 \\
\hline Pedagógica & 1 & 5 & 7 & 6 & - \\
\hline Programática $^{8}$ & 1 & 6 & 5 & 4 & - \\
\hline Transporte & 4 & 9 & 4 & 2 & 1 \\
\hline Instrumental $^{9}$ & 1 & 5 & 9 & 2 & 1 \\
\hline Comunicacional & 1 & 5 & 10 & 3 & - \\
\hline
\end{tabular}

Fonte: Elaboração própria.

Dos 19 coordenadores, 16 responderam que a acessibilidade atitudinal varia de péssima a regular. A mesma resposta foi dada ao serem questionados sobre a acessibilidade comunicacional. No caso da acessibilidade arquitetônica, 14 também responderam que ela varia de péssima a regular. Em relação à acessibilidade pedagógica, 13 apontaram que ela não passa de regular. Já no quesito acessibilidade programática, 12 avaliaram que ela não passa de regular. No caso da acessibilidade instrumental, 15 a qualificaram como péssima, ruim ou regular. Por último, a acessibilidade aos transportes se mostrou preocupante, pois 17 dos 19 a avaliaram como regular. Esses dados são preocupantes, pois mostram a fragilidade das instituições de

${ }^{7}$ A esse conjunto de pesquisas indicamos também aquelas desenvolvidas no âmbito do Observatório de Acessibilidade ao Ensino Superior. Parte dos resultados das investigações realizadas por eles fou publicada num dossiê temático pela Revista Ibero-Americana de Estudos em Educação (MARTINS; GIROTO; POKER, 2015). A produção científica e as atividades desenvolvidas pelo grupo encontram-se no site http://www.acessibilidadeinclusao.com.br/. Acessado em: junho de 2017.

${ }^{8}$ Barreiras invisíveis integradas em políticas públicas (leis, decretos, portarias) e normas ou regulamentos institucionais, etc.

${ }^{9}$ Barreiras em instrumentos, utensílios e ferramentas de estudo, de trabalho e de lazer ou recreação. 
ensino superior da região Sudeste no que diz respeito às diferentes dimensões da acessibilidade.

Sobre esses dados alguns aspectos chamam atenção. O primeiro se refere à acessibilidade atitudinal, pois ela não depende de obras e investimentos financeiros, mas sim de mudanças de atitudes em relação à diferença/deficiência. O que faz com que as pessoas ainda tenham tantos estereótipos sobre a deficiência? Como superar essa realidade? Que ações poderiam ser realizadas pelas IES nessa direção?

O tema da barreira atitudinal foi objeto da pesquisa de Silva (2016) realizada na Universidade Federal de Ouro Preto (UFOP). De acordo com a autora, as barreiras atitudinais passam pelos estereótipos concretizados a partir de comparações que docentes, alunos e técnicos fazem entre estudantes com deficiência e outros estudantes. Para mudar a cultura predominante que foca na "incapacidade", em detrimento das possibilidades das pessoas com deficiência, a iniciativa da Universidade Federal do Rio de Janeiro (UFRJ), teve uma iniciativa interessante ao criar o Fórum Permanente da UFRJ Acessível e Inclusiva para discutir com a comunidade os problemas relacionados às diferentes dimensões que envolvem a acessibilidade e a inclusão de pessoas com deficiências na instituição. Tal espaço acaba por esclarecer os participantes das possibilidades e, sobretudo, dos direitos educacionais e sociais das pessoas com deficiências, contribuindo, assim, para eliminar barreiras atitudinais (SOUZA et al, 2017).

O segundo aspecto diz respeito à falta de acessibilidade comunicacional. Nossos dados mostraram, assim como a pesquisa de Silva (2016), que as IES não haviam cumprido até o ano de 2014 as indicações da Lei de Acessibilidade, Lei nº 10.098 , de 19 de dezembro de 2000 (BRASIL, 2000). A maioria ainda não possuía sites, plataformas acadêmicas e outros serviços acessíveis sem os quais as pessoas com deficiência dependem do apoio de familiares e colegas para realizarem matrículas e ou se informarem.

Também coligimos dados sobre os serviços e recursos de tecnologias assistivas disponibilizados pelos núcleos aos estudantes com deficiência. O quadro 4 sintetiza essas informações. 
Quadro 4. Serviços e recursos disponibilizados pelos Núcleos de Acessibilidade das universidades federais do Sudeste

\begin{tabular}{|l|c|c|c|}
\hline Serviços e Recursos de Tecnologia Assistiva & Não & $\begin{array}{c}\text { Sim, } \\
\text { Insuficiente }\end{array}$ & $\begin{array}{c}\text { Sim, } \\
\text { Suficiente }\end{array}$ \\
\hline Tradutor e intérprete de LIBRAS & 3 & 14 & 2 \\
\hline Instrutor de LIBRAS & 13 & 6 & 0 \\
\hline Guia-intérprete & 19 & 0 & 0 \\
\hline Revisor Braille & 15 & 4 & 3 \\
\hline Transcritor Braille & 15 & 2 & 4 \\
\hline Material em Braille & 7 & 8 & 1 \\
\hline Material em Áudio & 6 & 10 & 1 \\
\hline Material didático em LIBRAS & 9 & 8 & 5 \\
\hline Material em formato impresso em carácter ampliado & 9 & 6 & 4 \\
\hline Material pedagógico tátil & 8 & 6 & 5 \\
\hline Material didático digital acessível & 7 & 9 & 4 \\
\hline Recursos de acessibilidade à comunicação & 5 & 10 & 4 \\
\hline Recursos de informática acessível & 1 & 13 & 3 \\
\hline Recursos para mobilidade & 5 & 11 & 0 \\
\hline Mobiliário escolar acessível & 10 & 7 & 2 \\
\hline Transporte acessível no âmbito da instituição & 11 & 6 & \\
\hline
\end{tabular}

Fonte: Elaboração própria.

No que diz respeito aos serviços e recursos de tecnologias assistivas, as respostas evidenciaram que a maioria dos NA carece de serviços de acessibilidade e não possui recursos de tecnologias assistivas. Por exemplo, no caso dos serviços, 15 universidades possuem tradutores e intérpretes de LIBRAS, mas 13 afirmam que este número é insuficiente. No caso dos instrutores de Libras, treze universidades não possuem este profissional e as 6 que o possuem afirmam que é insuficiente.

No caso do guia intérprete, verificamos que nenhuma universidade possuía profissional nessa área no período da pesquisa. Em relação aos revisores e transcritores de Braille, a situação não é muito diferente. Das universidades que responderam o questionário, 15 não possuem nenhum dos dois profissionais. Apenas 3 afirmaram que possuem transcritor em Braille de acordo com as suas demandas, enquanto as demais possuem tais profissionais em número insuficiente.

Ainda sobre os serviços e profissionais envolvidos nas ações dos núcleos, verificamos que alguns possuem também profissionais formados em Pedagogia, Psicopedagogia, Psicologia, Assistência Social, Terapia Ocupacional, Fisioterapia, Enfermagem, Sociologia, Engenharia Civil e bolsistas de diferentes áreas, assim como Técnicos Administrativos capacitados em áreas de interesse para realizar os apoios e serviços prestados pelos núcleos de acessibilidade. 


\section{Considerações finais}

Este artigo teve como objetivo apresentar resultados de uma pesquisa sobre a estrutura e o funcionamento dos Núcleos de Acessibilidade de 19 universidades federais do Sudeste, região de maior densidade acadêmica do país. A partir de um estudo quantitativo e descritivo constatamos as dificuldades das instituições para garantir a acessibilidade ao ensino superior de discentes com deficiências, transtornos globais do desenvolvimento e com altas habilidades/superdotação. Igualmente, apresentamos como se organizaram as equipes que atuam nos Núcleos de Acessibilidade e as ações que as mesmas desenvolvem para garantir o acesso, a participação plena dos discentes nas atividades acadêmicas.

Os resultados evidenciaram, ainda, diferentes problemas no que diz respeito à acessibilidade. Em especial, chamaram nossa atenção os dados relativos à acessibilidade atitudinal e comunicacional. Do mesmo modo, verificamos que a acessibilidade pedagógica, arquitetônica e nos transportes merece cuidadoso debate nas IFES. Também não podemos deixar de evidenciar a falta e carência de profissionais especialistas como intérpretes, tradutores e instrutores de LIBRAS, assim como de revisores e transcritores em Braille. Sabemos que essa demanda depende de liberação de vagas pelo Ministério do Planejamento e de recursos para contratos, mas antes disso as instituições precisam inserir efetivamente o debate sobre inclusão e acessibilidade em seus Planos de Desenvolvimento Institucional.

Diante do exposto, esperamos que os dados aqui apresentados, assim como as nossas inferências, possam contribuir com informações e reflexões para que as IFES possam avançar e melhorar as condições de acesso, permanência e participação da população com deficiência, transtorno global do desenvolvimento e altas habilidades nas atividades acadêmicas. Esperamos que o compromisso assumido pelo poder público, a partir da promulgação da Lei de Cotas, implique também em aumento do orçamento para as instituições.

Entendemos que ampliar a acessibilidade ao ensino superior exige mais investimentos financeiros, mas também pesquisas que privilegiem o tema e suas dimensões frente às políticas de inclusão. Sem pesquisas empíricas que analisem as formas sob as quais essa política educacional se traduz no ensino superior, não há como identificar e problematizar as experiências bem ou mal sucedidas, assim como as reais demandas colocadas para efetivar tal processo. 
É importante sinalizar, ainda, que apesar das dificuldades e problemas enfrentados pelas IFES, sobretudo no que diz respeito à carência de recursos humanos capacitados em áreas específicas para o suporte e apoio pedagógico, todas as IFES da Região Sudeste estão cumprindo as diretrizes federais e implementando os NA a partir de suas condições e realidades institucionais locais. Finalizamos, assim, com as palavras de Milton Nascimento: "se muito vale o já feito, mais vale o que será".

\section{REFERENCIAS}

BRASIL. Lei $\mathbf{n}^{\mathbf{0}} \mathbf{1 0 . 0 9 8}$ de 19 de dezembro de 2000. Disponível em:

<http://www.planalto.gov.br/ccivil_03/leis/L10098.htm>. Acesso em: 16 jun. 2017.

\section{BRASIL. Ministério da Educação. Política Nacional de Educação Especial na perspectiva da Educação Inclusiva. Brasília: MEC/SECADI, 2008a.}

BRASIL. Secretaria de Educação Superior. Edital no 4. Seleção de Propostas. Programa Incluir: acessibilidade na educação superior. Diário Oficial [da] República Federativa do Brasil, Poder Executivo, Brasília, DF, 2008b, Seção 3, 39-40. Disponível em: $<$ http://portal.mec.gov.br/index.php?option=com_docman\&view=download \&alias=816-incluir-propostas-pdf \&category_slug=documentos-pdf\&Itemid=3019> . Acesso em: 08 jun. 2017.

BRASIL. Decreto no. 7. 611, de 17 de novembro de 2011. Disponível em: <http://www.planalto.gov.br/ccivil_03/_ato2011-2014/2011/decreto/d7611.htm>. Acesso em: 10 jun. de 2017.

BRASIL. Decreto $\mathbf{n}^{0}$. 6.949, de 25 de agosto de 2009. Disponível em: <http://www.planalto.gov.br/ccivil_03/_ato2007-2010/2009/decreto/d6949.htm>. Acesso em: 13 jun. 2017.

BRASIL. Lei no 12.711, de 29 de agosto de 2012 (2012a). Dispõe sobre o ingresso nas universidades federais e nas instituições federais de ensino técnico de nível médio e dá outras providências. Disponível em: <http://www.planalto.gov.br/ccivil_03/_ato20112014/2012/lei/112711.htm>. Acesso em: 02 jun. 2017.

BRASIL. Resolução no . 466, de 12 de dezembro de 2012 (2012b). Aprova diretrizes e normas regulamentadoras de pesquisas envolvendo seres humanos. Brasília, DF.

Disponível em:

<http://bvsms.saude.gov.br/bvs/saudelegis/cns/2013/res0466_12_12_2012.html>. Acesso em: 28 jun. 2015.

BRASIL. Programa Incluir. Documento Orientador Programa Incluir Acessibilidade na Educação Superior SECADI/SESu (2013). Disponível em:<file:///C:/Users/saionara\%20pussente/Downloads/documento_orientador_programa _incluir\%20(2).pdf>. Acesso em: 10 jun. de 2017. 
BRASIL. Lei no 13.146 de 6 de julho de 2015. Institui a Lei Brasileira de Inclusão da Pessoa com Deficiência (Estatuto da Pessoa com deficiência). Disponível em: <http://www.planalto.gov.br/ccivil_03/_ato2015-2018/2015/lei/113146.htm>. Acesso em: 02 jun. de 2017.

BRASIL. Ministério da Educação. A consolidação da inclusão escolar no Brasil (2003-2016). Brasília: MEC, 2016a.

BRASIL. Lei $\mathbf{n}^{\mathbf{0}}$. 13.409, de 28 de dezembro de 2016 (2016b). Altera a Lei $\mathrm{n}^{0}$ 12.711, de 29 de agosto de 2012, para dispor sobre a reserva de vagas para pessoas com deficiência nos cursos técnico de nível médio e superior das instituições federais de ensino. Disponível em: <http://www.planalto.gov.br/ccivil_03/_ato2015-

2018/2016/lei/L13409.htm>. Acesso em: 06 jun. 2017.

BRUNO, M. M. G. Políticas afirmativas para a inclusão do surdo no ensino superior: algumas reflexões sobre o acesso, a permanência e a cultura universitária. R. bras. Est. pedag., Brasília, v. 92, n. 232, p. 542-556, set./dez. 2011.

CABRAL, L. S. A.; MELO, F. R. L. V. de. Entre a normatização e a legitimação do acesso, participação e formação do público alvo da Educação Especial em Instituições de Ensino Superior Brasileiro. Educar em Revista, 2017 (no prelo).

DUARTE, E. R. A inclusão de pessoas com deficiências nas instituições de ensino superior e nos cursos de Educação Física de Juiz de Fora pede passagem. $E$ agora? 2009. 163f. Dissertação (Mestrado em Educação), Universidade Federal de Juiz de Fora, Juiz de Fora, 2009.

MANZINI, E. J. Inclusão e acessibilidade. In: Revista da Sociedade Brasileira de Atividade Motora Adaptada - Sobama, São Paulo, v. 10, n. 1, p. 31-36, Suplemento, dez. 2005.

MARTINS, D. A.; LEITE, L. P.; BROGLIA, C. L. Políticas públicas para acesso de pessoas com deficiência ao ensino superior brasileiro: uma análise de indicadores educacionais. In: Revista Ensaio: Avaliação e Políticas Públicas em Educação, Rio de Janeiro, v. 23, n. 89, p. 984-1014, nov. 2015. ISSN 1809-4465. Disponível em: <http://revistas.cesgranrio.org.br/index.php/ensaio/article/view/772>. Acesso em: 7 set. 2016.

MARTINS, S. E. S. O; GIROTO, C.R.M; POKER, R.B.P.; Políticas de inclusão e formação na educação superior. In: Revista Iberoamerica de Estudos em Educação, Araraquara: FClar/ Unesp, v. 10, n. especial. 2015 . Disponível em: < http://seer.fclar.unesp.br/iberoamericana/issue/view/528>. Acesso em: 07 jun. 2017.

MELO, F. R. L. V. de. O Programa Incluir na Universidade Federal do Rio Grande do Norte: conquistas e desdobramentos institucionais. In: MENDES, E. G.; ALMEIDA, M. A. (orgs.). Educação Especial Inclusiva: legados históricos e perspectivas, Marilia, São Paulo: UNESP, 2015, p. 273-286.

MELO, F. R. L. V. de.; MARTINS, M. H. Legislação para estudantes com deficiência 
no Ensino Superior no Brasil e em Portugal: algumas reflexões. In: Revista Acta Scientiarum. Education (Online), v. 38, p. 259-269, 2016.

MELO, F. R. L. V. de.; MARTINS, M. H. V.; MARTINS, S. C. Estudantes com deficiência no ensino superior - serviços de apoio: organização, desafios e reflexões. São Paulo, 2017. (no prelo)

MOREIRA, S. C. P. C. A inclusão de alunos com necessidades educacionais especiais no ensino superior: um estudo de caso sobre a implementação do Núcleo de Inclusão no IM/UFRRJ. 2015. 45f. Monografia (Graduação em Pedagogia), Universidade Federal Rural do Rio de Janeiro Campus de Nova Iguaçu, Nova Iguaçu, 2015.

MOREIRA, S. C. P. C. Inclusão de alunos com deficiência no ensino superior: uma análise da região sudeste. 2017. 69 f. Projeto de qualificação de Mestrado. Programa de Pós-Graduação em Educação, Contextos Contemporâneos e Demandas Populares da Universidade Federal Rural do Rio de Janeiro, 2017.

PEREIRA, C. E. C. Inclusão no Ensino Superior: percepção de serviços públicos docentes e não docentes sobre a inclusão no Brasil e em Portugal. 2017. Tese (Doutorado em Educação Escolar). Faculdade de Ciências e Letras. UNESP/ Bauru, 2017.

PLETSCH, M. D.; LEITE, L. P. Análise da produção científica sobre inclusão no ensino superior. Educar em Revista, 2017 (no prelo).

REIS N. M. de M. Política de inclusão escolar de pessoas com necessidades educacionais especiais no ensino superior e as universidades federais mineiras. 2010. 188f. Dissertação (Mestrado em Educação), Universidade Federal de Minas Gerais, Belo Horizonte, 2010.

SARAIVA, L. L. O. Núcleos de Acessibilidade e o Atendimento de alunos com necessidades especiais nas Universidades Federais do Nordeste Brasileiro. 192f. Dissertação (Mestrado em Educação), Universidade Federal do Rio Grande do Norte, Natal, 2015.

SILVA, M. M. da. Inclusão de estudantes com deficiência no ensino superior: questões atitudinais, físicas e comunicacionais. In: Seminário Internacional de Inclusão em Educação: Universidade e Participação, 4, 2016, Anais... Rio de Janeiro, 2016.

SOUZA, B. C. S. de. Programa Incluir (2005-2009): uma iniciativa governamental da Educação Especial na Educação Superior. 179f. Dissertação (Mestrado em Educação), Universidade Federal de Santa Catarina, 2010.

SOUZA, I. M. G.; COHEN, R.; CARREIRA, P. L. C.; DIAS, A. F. da S. HOUZEL, J. C. $A$ inclusão no ensino superior: implementação de políticas de acessibilidade na universidade federal do Rio de Janeiro. Disponível em:

<http://editorarealize.com.br/revistas/cintedi/trabalhos/TRABALHO_EV060_MD1_SA 12_ID3586_20102016094538.pdf>. Acesso em: 10 jun. 2017. 


\section{Como referenciar este artigo}

PLETSCH, Marcia Denise.; MELO, Francisco Ricardo Lins Vieira de. Estrutura e funcionamento dos Núcleos de Acessibilidade nas Universidades Federais da Região Sudeste. Revista Ibero-Americana de Estudos em Educação, Araraquara, v. 12, n. 3, p. 1610-1627, jul./set. 2017. Disponível em: <http://dx.doi.org/10.21723/riaee.v12.n.3.2017.10354>. E-ISSN: 1982-5587.

Submetido em: 05/05/2017

Aprovação final em: 10/08/2017 